\title{
Antidiabetic and gastric emptying inhibitory effect of herbal Melia azedarach leaf extract in rodent models of diabetes type 2 mellitus
}

This article was published in the following Dove Press journal:

Journal of Experimental Pharmacology

20 March 2017

Number of times this article has been viewed

\section{Daniel Seifu' ${ }^{1,2}$ \\ Lars E Gustafsson ${ }^{3}$ \\ Rajinder Chawla' \\ Solomon Genet' \\ Asfaw Debella ${ }^{4}$ \\ Mikael Holst ${ }^{5}$ \\ Per M Hellström²}

'Department of Biochemistry, College of Health Sciences, School of Medicine, Addis Ababa University, Addis Ababa, Ethiopia; ${ }^{2}$ Department of Medical Sciences, Uppsala University, Uppsala, ${ }^{3}$ Department of Physiology and Pharmacology, Karolinska Institutet, Stockholm, Sweden; ${ }^{4}$ Department of Traditional Drug Development, Ethiopian Health and Nutrition Research Institute, Addis Ababa, Ethiopia; ${ }^{5}$ Department of Women's and Children's Health, Karolinska Institutet, Stockholm, Sweden
Correspondence: Per M Hellström Department of Medical Sciences, Uppsala University Hospital, Uppsala University, Building 40, Fifth floor, SE-75I 85 Uppsala, Sweden

$\mathrm{Tel}+46$ I8 6II 4285

Fax +46 I8 509297

Email Per.Hellstrom@medsci.uu.se
Abstract: Diabetes type 2 is associated with impaired insulin production and increased insulin resistance. Treatment with antidiabetic drugs and insulin strives for normalizing glucose homeostasis. In Ethiopian traditional medicine, plant extracts of Melia azedarach are used to control diabetes mellitus and various gastrointestinal disorders. The objective of this study was to clarify the antidiabetic effects of $M$. azedarach leaf extracts in diabetic type 2 experimental animals. In this study, mice were injected with Melia extract intraperitoneally. Plasma glucose was studied by using tail vein sampling in acute experiments over $4 \mathrm{~h}$ and chronic experiments over 21 days with concurrent insulin and body weight assessments. Glucose tolerance was studied by using intraperitoneal glucose $(2 \mathrm{mg} / \mathrm{g})$ tolerance test over $120 \mathrm{~min}$. Gastric emptying of a metabolically inert meal was studied by the gastric retention of a radioactive marker over $20 \mathrm{~min}$. Melia extracts displayed acute, dose-dependent antidiabetic effects in ob/ob mice similar to glibenclamide $(p<0.05-0.001)$. Long-term administration of Melia extract reduced plasma glucose $(p<0.001)$ and insulin $(p<0.01-0.001)$ levels over 21 days, concurrent with body weight loss. Glucose tolerance test showed reduced basal glucose levels $(p<0.05-0.01)$, but no difference was found in glucose disposal after long-term treatment with Melia extract. In addition, the Melia extract at $400 \mathrm{mg} / \mathrm{kg}$ slowed gastric emptying rate of normal Sprague-Dawley $(p<0.001)$ and diabetic Goto-Kakizaki rats $(p<0.001)$ compared with controls. It is concluded that the $M$. azedarach leaf extract elicits diabetic activity through a multitargeted action. Primarily an increased insulin-sensitizing effect is at hand, resulting in blood glucose reduction and improved peripheral glucose disposal, but also through reduced gastric emptying and decreased insulin demand.

Keywords: ob/ob mouse, Sprague-Dawley, Goto-Kakizaki, glucose tolerance test

\section{Introduction}

The World Health Organization (WHO) Expert Committee on diabetes mellitus has recommended traditional medicinal herbs to be further investigated ${ }^{1}$ for the development of new efficient antidiabetic drugs for the treatment of diabetes, and WHO has estimated that $>1,200$ plant species are used to treat diabetes, primarily in the developing world. ${ }^{2}$ These species represent $>725$ genera in 183 families, ranging from marine algae to higher plants. ${ }^{3}$ However, only about 350 of them have been documented to present antihyperglycemic activity, ${ }^{4}$ and few have been subjected to rigorous scientific evaluation for safety and efficacy in human beings. ${ }^{5,6}$

Melia azedarach Linn. belongs to the family Meliaceae and is an exotic plant that is well adapted to Ethiopian conditions. This plant is commonly available and grown as a street tree in many villages. From antiquity, every part of this tree has been used as traditional medicines for household remedy against various human ailments: the 
plant has been traditionally used for the treatment of leprosy, inflammations, and cardiac disorders, ${ }^{7,8}$ its fruit extracts possess ovicidal ${ }^{9}$ and larvicidal activity; ${ }^{10}$ and the leaf extracts possess antiviral, ${ }^{11}$ contraceptive, ${ }^{12}$ and antioxidant activity. $^{7}$ Recently, a bioactivity-guided chemical analysis of $M$. azedarach has shown antidiabetic activity with inhibitory effects on protein tyrosine phosphatase-1B enzyme as well as glucose uptake stimulation in $\mathrm{C} 2 \mathrm{Cl} 2$ myoblasts cells. ${ }^{13}$ Even though it is used commonplace for the treatment of diabetes mellitus, its precise antihyperglycemic actions in vivo have not been studied in detail.

The aim of the present study was to assess the antidiabetic properties of the Melia leaf extracts in spontaneously diabetic mice and rats to disentangle the antidiabetic properties of this plant and explore its mechanisms of action.

\section{Materials and methods}

\section{Plant material and preparation of aqueous leaf extract}

The leaves of $M$. azedarach were collected in the southern part of Ethiopia. The plant was identified by a taxonomist (Department of Traditional Drug Development, Ethiopian Health and Nutrition Research Institute, Addis Ababa, Ethiopia). A voucher specimen (MA-2106) has been deposited in the herbarium of the institute; $1 \mathrm{~kg}$ of $M$. azedarach leaves was grounded by using an electrical mill. The powder was macerated in distilled water for $6 \mathrm{~h}$. The maceration was carried out on a shaker, and lumps were removed by sieving through gauze. The solution was lyophilized overnight to yield $78 \mathrm{~g}$ of yellowish powder, and this powder, reconstituted in aqueous media, was used for studying antidiabetic effects in diabetic type $2 \mathrm{ob} / \mathrm{ob}$ mice and for determining the gastric emptying rate in rats.

\section{Experimental animals}

Male ob/ob mice (49-52 g, 10-18 weeks old) and male GotoKakizaki (GK) rats (300-400 g) were obtained from the breeding colony at Karolinska Institutet. Male Sprague-Dawley (SD) rats (300-350 g) were purchased from Scanbur BK AB (Sollentuna, Sweden). All the animals were housed in wire-meshed cages at $24^{\circ} \mathrm{C}$ with constant humidity and $12: 12 \mathrm{~h}$ light-dark cycle. The animals were fed ad libitum with a rodent pellet diet (R36 Labfor, Lactamin, Lantmännen, Kimstad, Sweden) and tap water, except when fasted before experiments, when animals had access to only water. Animal welfare and handling procedures were in accordance with the guidelines of the Guide for the Care and Use of Laboratory Animals which was published by the US National Institutes of Health (Publication No. 85-23). The experimental protocols were approved by the Northern Stockholm Animal Ethics Committee.

\section{Study design}

Short-term antidiabetic effects of $M$. azedarach leaf extracts

For this experiment, $30 \mathrm{ob} / \mathrm{ob}$ mice were randomly assigned to 5 treatment groups (each $n=6$ ). The mice were treated with intraperitoneal (IP) injections of the Melia extracts (ie, 200, 300 , and $400 \mathrm{mg} / \mathrm{kg}$ ) or saline as a negative control and glibenclamide $(5 \mathrm{mg} / \mathrm{kg})$ as a positive control. Tail vein plasma glucose was measured at $0,1,2,3$, and $4 \mathrm{~h}$ posttreatment (Accu-Check, Roche Diagnostics, Indianapolis, IN, USA).

\section{Long-term antidiabetic effects of $M$. azedarach leaf extracts}

For this experiment, $24 \mathrm{ob} / \mathrm{ob}$ mice were randomly divided into 4 treatment groups (each $n=6$ ). The Melia extract of 200 or $400 \mathrm{mg} / \mathrm{kg}$ or saline as a negative control and glibenclamide $(5 \mathrm{mg} / \mathrm{kg}$ ) as a positive control were injected daily for 3 weeks in a row. Tail vein plasma glucose was measured (Accu-Check) on days 1, 5, 10, 15, and 20 posttreatments. Plasma insulin was measured from tail vein blood samples of $0.5 \mathrm{~mL}$ collected on days $1,7,14$, and 21 posttreatment. Blood samples were collected in heparinized tubes, centrifuged at 4,000 rpm for $10 \mathrm{~min}$, plasma pipetted off and stored at $20^{\circ} \mathrm{C}$ for insulin radioimmunoassay. ${ }^{14}$

An IP glucose tolerance test (IPGTT) was conducted before and after the 3-week study period with Melia extract or glibenclamide. The mice were fasted for $4 \mathrm{~h}$ and then given an IP glucose load ( $2 \mathrm{mg} / \mathrm{g})$. Blood samples were collected at $0,30,60,120$, and $180 \mathrm{~min}$ for the analysis of glucose disposal and elimination from the circulation (each group $n=6$ ).

\section{Effects of M. azedarach leaf extracts on gastric emptying rate}

In this experiment, 12 each of SD and GK rats were used. After anesthesia (pentobarbital 50 mg/kg IP; Apoteksbolaget, Umeå, Sweden), an abdominal incision was made, and a gastric catheter was implanted at the greater curvature. One catheter was pulled under the skin to exit at the back of the right ear, and another catheter was inserted into the jugular vein to exit at the back of the left ear. After surgery, each rat was housed singly to recover for 7 days. Before experiments, the rats were fasted for $6 \mathrm{~h}$.

To evaluate the effect of $M$. azedarach on gastric emptying rate, leaf extract of $400 \mathrm{mg} / \mathrm{kg}$ was given to the rats intragastrically in $1.5 \mathrm{~mL} 0.1 \%$ dimethylcellulose with $0.3 \mathrm{~mL}$ 1.47 $\mathrm{MBq}^{51} \mathrm{Cr}$-EDTA as vehicle ( $\mathrm{SD}, \mathrm{n}=6$; GK, $\mathrm{n}=6$ ). Control rats were given $1.5 \mathrm{~mL}$ of vehicle alone $(\mathrm{SD}, \mathrm{n}=6$; $\mathrm{GK}, \mathrm{n}=6)$. After $20 \mathrm{~min}$, the rats were sacrificed with a pentobarbital overdose, the abdomen was opened, pylorus and lower 
esophagus were ligated, and stomach was removed en bloc. The radioactivity remaining in the stomach was calculated by using a gamma counter (Wallac Wizard, Turku, Finland) for $60 \mathrm{~s}$. Gastric emptying was determined as the percentage of radioactive marker retained in the stomach. The time period of $20 \mathrm{~min}$ was chosen as this has previously been shown to correspond to $50 \%$ gastric emptying. ${ }^{15}$

\section{Data and statistical analysis}

Data were expressed as mean and standard error of the mean. Statistical significance between the animals treated with Melia extract and controls was determined by using paired or unpaired Student's $t$-test or analysis of variance for repeated measures as appropriate; $p<0.05$ was considered significant.

\section{Results}

\section{Effect of graded doses of M. azedarach extracts on glucose in ob/ob mice}

In all the mice, fasting plasma glucose values were typically hyperglycemic in all study groups before administration of the Melia leaf extract, saline, or glibenclamide. The Melia leaf extract of 200,300 , and $400 \mathrm{mg} / \mathrm{kg}$ IP lowered the blood glucose levels at all the time points $(p<0.05-0.001)$. The effect was dose- and time-dependent with a blood glucose reduction of $18 \%$ at $1 \mathrm{~h}, 48 \%$ at $2 \mathrm{~h}, 60 \%$ at $3 \mathrm{~h}$, and $64 \%$ at $4 \mathrm{~h}$ with $200 \mathrm{mg} / \mathrm{kg} ; 20 \%$ at $1 \mathrm{~h}, 36 \%$ at $2 \mathrm{~h}, 59 \%$ at $3 \mathrm{~h}$, and $62 \%$ at $4 \mathrm{~h}$ with $300 \mathrm{mg} / \mathrm{kg}$; and $30 \%$ at $1 \mathrm{~h}, 57 \%$ at $2 \mathrm{~h}$, $64 \%$ at $3 \mathrm{~h}$, and $67 \%$ at $4 \mathrm{~h}$ with $400 \mathrm{mg} / \mathrm{kg}$. Glibenclamide had a comparable glucose-lowering effect, whereas saline had not (Figure 1).

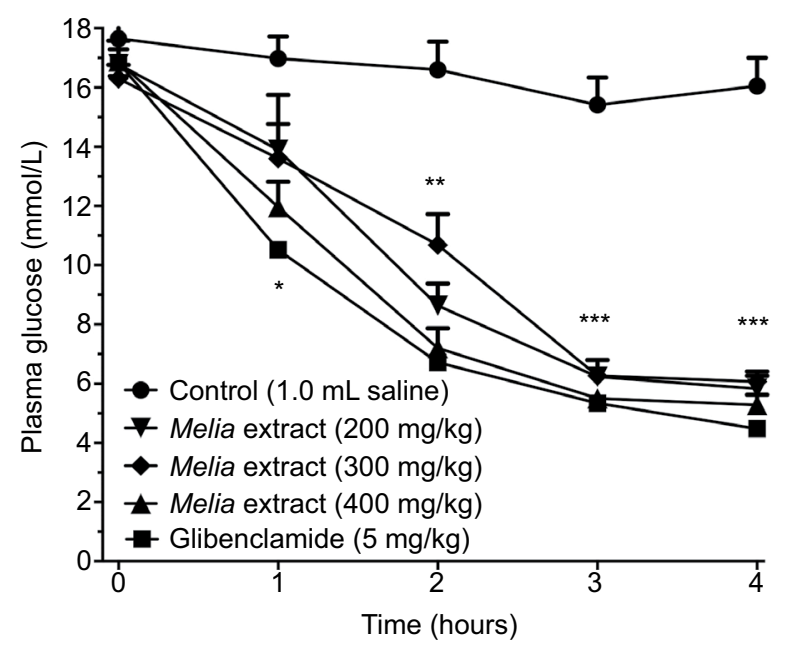

Figure I Antidiabetic effects of graded intraperitoneal dose effect of Melia azedarach aqueous leaf extracts $(200,300$, and $400 \mathrm{mg} / \mathrm{kg})$ on plasma glucose level in ob/ob mice over a period of $4 \mathrm{~h}$.

Notes: Results were expressed as mean \pm standard error. ${ }^{*} p<0.05,{ }^{* *} p<0.0$ I, and $* * * p<0.001$.
Long-term effects of $M$. azedarach extract on glucose, insulin, and body weight in ob/ob mice

Fasting plasma glucose level showed similar hyperglycemia in all study groups before the administration of the Melia leaf extract, saline, or glibenclamide. The Melia leaf extract of 200 and $400 \mathrm{mg} / \mathrm{kg}$ IP per day showed a parallel fasting glucose reduction as did glibenclamide (all $p<0.001$ ) over the 3-week treatment period, and saline had no effect (Figure 2A).

Fasting insulin levels confirmed hyperinsulinemia in all study groups ranging from 132 to $151 \mu \mathrm{U} / \mathrm{mL}$. Over the 3-week treatment period with Melia leaf extracts of 200 or $400 \mathrm{mg} / \mathrm{kg}$ IP per day, insulin levels progressively decreased $(p<0.01-0.001)$. With Melia extract of $200 \mathrm{mg} / \mathrm{kg}$, plasma insulin level decreased by $52 \%$ on day $7,57 \%$ on day 14 , and
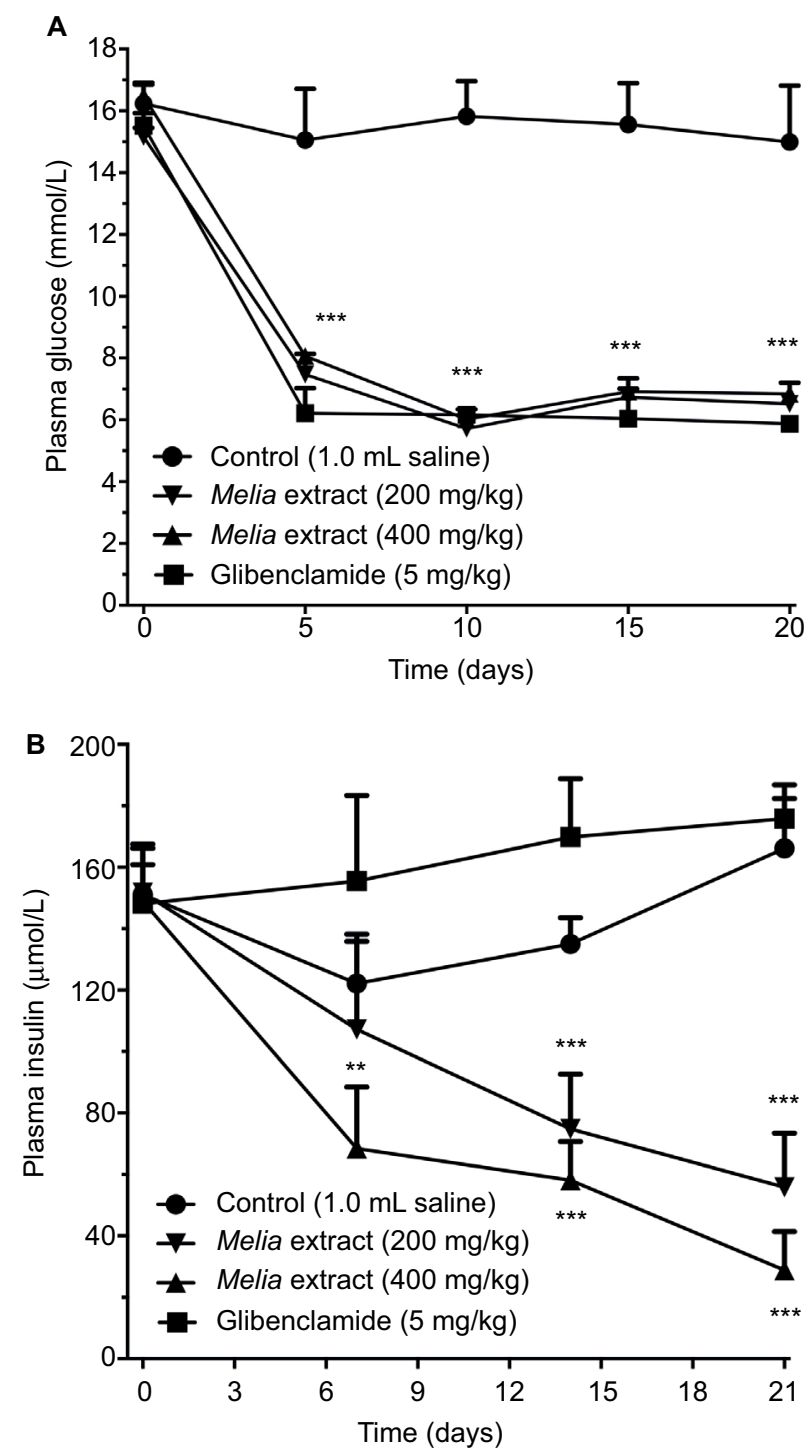

Figure 2 Long-term effect of Melia azedarach aqueous leaf extract (200 or $400 \mathrm{mg} / \mathrm{kg}$ ) or glibenclamide $(5 \mathrm{mg} / \mathrm{kg}$ ) on plasma glucose (A) and insulin (B) levels in ob/ob mice over a study period of 3 weeks.

Notes: Results are expressed as mean \pm standard error. ${ }^{* *} p<0.01$, **** $p<0.001$. 
$73 \%$ on day 21 as compared with controls; with $400 \mathrm{mg} / \mathrm{kg}$, plasma insulin level decreased by $62 \%$ on day $7,69 \%$ on day 14 , and $78 \%$ on day 21 . Under treatment with glibenclamide or saline, insulin levels remained unchanged (Figure 2B).

After a 4-h fasting period, the mice showed basal hyperglycemia that responded to IPGTT with a plasma glucose peak from $\sim 13$ up to $\sim 23 \mathrm{mmol} / \mathrm{L}$. After the 3-week course of treatment with Melia extract or glibenclamide, basal glucose was moderated to $\sim 10 \mathrm{mmol} / \mathrm{L}(p<0.05-0.01)$, reaching a top level of $\sim 19 \mathrm{mmol} / \mathrm{L}$ upon IPGTT. With this challenge, there was no difference in the plasma glucose incremental increase and glucose disposal between treatments with Melia extract and glibenclamide (Figure 3A-C).

The weight of the control rats on day 1 was $51.1 \pm 0.4 \mathrm{~g}$ and then increased slightly to $53.2 \pm 0.4 \mathrm{~g}$ on day 21 . During treatment with Melia leaf extract $200 \mathrm{mg} / \mathrm{kg}$ per day, body weight decreased numerically by $4 \%$ compared with the control group at day 21 . Similarly, $400 \mathrm{mg} / \mathrm{kg}$ per day reduced body weight by $6 \%$ when compared with the control group. Glibenclamidetreated mice did not differ from controls in terms of body weight increase of $2 \%$ as compared with controls.

\section{Effect of $M$. azedarach extract on gastric emptying rate in rats}

In nondiabetic SD rats, Melia leaf extract of $400 \mathrm{mg} / \mathrm{kg}$ caused a 2-fold increase in gastric meal retention, indicating slowed gastric emptying rate as compared with controls $(p<0.001)$. In diabetic GK rats with a plasma glucose of $11.8 \pm 0.6 \mathrm{mmol} / \mathrm{L},{ }^{16}$ the gastric retention was increased by 2.4 -fold compared with control diabetic GK rats ( $p<0.001$; Figure 4$)$.

\section{Discussion}

This study investigated the antidiabetic effects of $M$. azedarach leaf extracts in rodent models of diabetes type 2; in most experiments, the effects of the Melia extract were compared to those of glibenclamide, which was a positive control. The ob/ob mice were used as an experimental model. Obesity was a common feature of these animals due to a mutation in the leptin gene. Animals that are homozygous for this mutation exhibited morbid obesity and metabolic abnormalities, including hyperglycemia, glucose intolerance, and hyperinsulinemia, which resemble the human diabetes type 2 phenotype. ${ }^{17}$ The GK rat was also used as another model of diabetes. This rat exhibited a less severe phenotype of diabetes type 2 than that exhibited by the ob/ ob mouse with only slightly elevated blood glucose and no obesity. ${ }^{18}$ Gastric emptying and gastrointestinal motility in the GK rat was easy to study and has previously been shown to be akin to the SD rat, both being representatives of human conditions. ${ }^{19}$ The variables used for this analysis should be representatives of the systemic dynamic response to a meal and could easily be monitored by repeat plasma samples. Hence, the short-term effect and the long-term effect of the Melia extracts were studied by using blood sampling with an analysis of plasma glucose and insulin. In relation to this, gastric emptying was studied as the nutritional load presented to the small intestine for absorption, and release of incretins should be of major importance for metabolic control as previously known from glucagon-like peptide-1 (GLP-1). ${ }^{19,20}$ There are numerous other metabolic biomarkers to study in hyperglycemic dysregulation, which should, in detail, outline cellular changes due to oxidative stress, such as superoxide from the monocytes, oxidized low-density lipoprotein, and nitrotyrosine. However, the measurements of these biomarkers should regularly be normalized to the body mass index, ${ }^{21}$ why such an approach seems less feasible in the rodents.

In acute dose-response experiments in ob/ob mice, it was found that the plasma glucose level fell progressively within
A

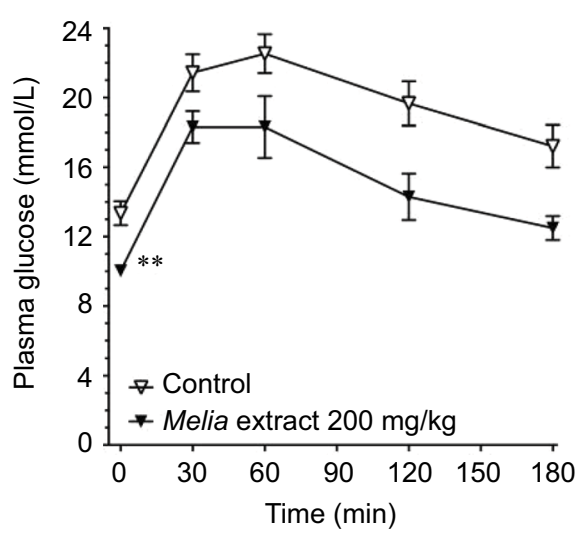

B

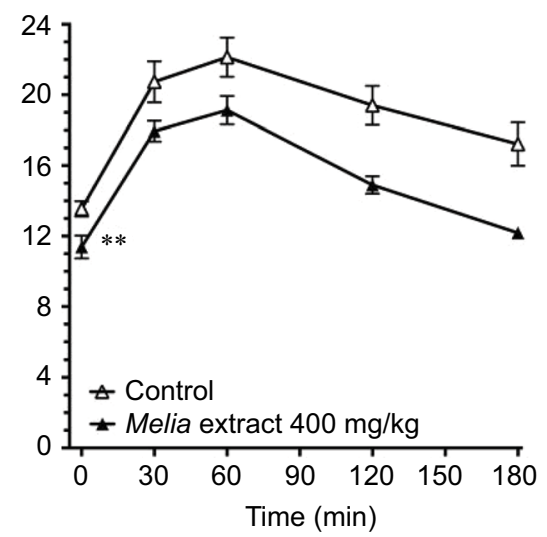

C

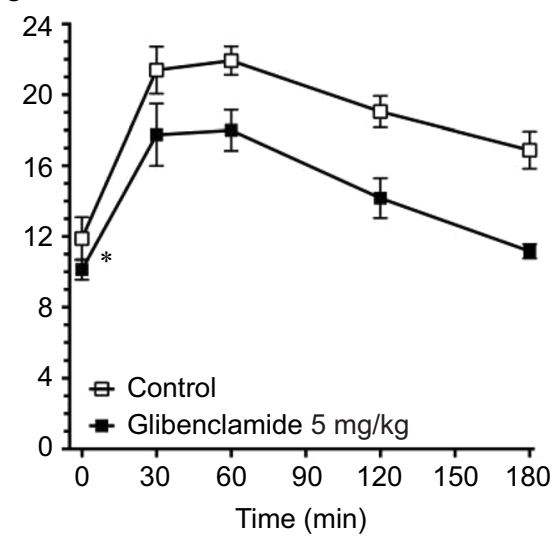

Figure 3 Intraperitoneal glucose tolerance test on ob/ob mice treated with (A) Melia azedarach leaf extract (200 mg/kg), (B) M. azedarach leaf extract (400 mg/kg), and (C) glibenclamide $(5 \mathrm{mg} / \mathrm{kg})$ before and after a treatment period of 3 weeks.

Notes: Results are expressed as mean \pm standard error. ${ }^{*} p<0.05$, ${ }^{* *} p<0.01$. Two tests were done with an interval of 3 weeks; each test covers a 180 min period. 


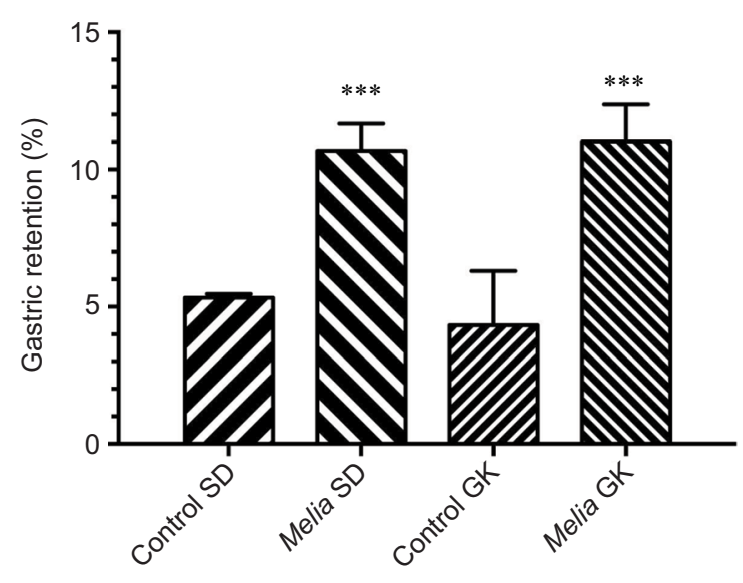

Figure 4 Effects of Melia azedarach aqueous leaf extract on gastric emptying rates in Sprague-Dawley (SD) and Goto-Kakizaki (GK) rats.

Notes: Results are expressed as mean \pm standard error. ${ }^{* * *} p<0.001$.

few hours with increasing dosage of the extract and was maintained at normal levels of $5-6 \mathrm{mmol} / \mathrm{L}$. After chronic treatment with the Melia extract during a 3-week period in the ob/ob mice, plasma glucose levels were maintained at a low level, indicating that no desensitization to the pharmacological action of the extract took place over the 3-week period. In a similar manner, serum insulin decreased during treatment with the Melia extract. Conversely, the glibenclamide-treated group displayed unchanged plasma insulin levels.

IPGTT revealed that the Melia extract lowered basal plasma glucose and hence dampened the absolute glucose excursions after challenge, while the change in glucose level was not different, and glucose clearance from plasma was not affected. This would indicate that the Melia extract primarily exerted a long-term antidiabetic effect similar to sulphonylurea (glibenclamide), but did not promote an immediate insulin release upon challenge ${ }^{22}$ as shown in the present experiments. An insulin-sensitizing effect of Melia is further substantiated by the marked decrease in insulin that took place during the long-term treatment with the Melia extract over weeks. Hence, the extract of Melia significantly improves glucose homeostasis by actions in the peripheral tissues, most likely liver, adipose tissue, and skeletal muscle. ${ }^{23}$

The ability of insulin to mediate tissue glucose uptake is critical in maintaining glucose homeostasis and clearance of the postprandial glucose load. ${ }^{24-26}$ As patients with diabetes type 2 generally exhibit a marked insulin resistance with a reduction in insulin-mediated glucose disposal, ${ }^{20,24,27}$ the effect of Melia may come into play as an enhancer of insulin treatment.

In addition to its direct effects on glucose disposal, the Melia extract was found to decrease body weight. Even though this effect is clearly distinct from an insulin-sensitizing effect, the resulting loss of body weight is advantageous in the dia- betic state. A possible explanation for the slight body weight loss that was observed in the long-term studies of ob/ob mice was found in the supplementary studies that had been carried out in normal SD and diabetic GK rats where gastric emptying was markedly slowed by the Melia extract. The slow rate of gastric emptying is also interesting in light of the diabetes type 2 phenotype where sizable overweight is usually at hand. Gastric emptying can be considered the first step in the endocrine response to a meal. Slow rate of gastric emptying would lead to a slower nutrient exposure and absorption and less demand of insulin for glucose disposal. This is to be taken as advantageous in diabetes type 2 . A similar effect was clearly shown by the endocrine GLP-1 response to eating where gastric emptying was inhibited as well as insulin release was stimulated. ${ }^{28}$ Furthermore, slow rate of gastric emptying also increases satiety sensations after a meal and decreases food intake and body weight control, ${ }^{29}$ which leads to a beneficial weight loss in diabetics, hence reducing insulin resistance and insulin demands. In the present experiments, the Melia extract had a significant inhibitory effect on gastric emptying, which may underlie the reduced insulin release in the long-term experiments, whereas the following body weight loss was less marked during the 3 weeks of study and therefore seems to be of less importance for glucose homeostasis.

Similar to the Melia extract, other plant extracts have shown antidiabetic effects. The hydroalcoholic extract of $A$. indica has shown antihyperglycemic effects in normal, glucose-fed, and streptozotocin diabetic rats. ${ }^{30}$ The Azadirachta indica plant exerts its pharmacological activity independently of insulin and blocks the action of epinephrine on glucose metabolism, thus increasing peripheral glucose utilization. ${ }^{30}$ It also increases glucose uptake and glycogen deposition in the isolated rat hemidiaphragm..$^{30}$ These data speak in favor of a peripheral action of this plant extract. However, no studies on gastric emptying as a counterbalancing effect to increased glucose utilization have been carried out.

\section{Conclusion}

In the research of antidiabetic mechanisms of various Ethiopian medicinal herbs, it was found that the lyophilized aqueous extract of $M$. azedarach has the power to maintain adequate plasma glucose homeostasis in diabetic mice and rats. The mechanism underlying this antihyperglycemic activity was shown to be dual with actions on both insulin sensitivity and gastric emptying rate, thus meeting drug discovery requirements of a rigorous scientific evaluation for a plausible mechanism of action for its deliberate use in the treatment of diabetes type 2 in Ethiopia. 


\section{Acknowledgments}

This study was supported by Swedish International Development Cooperation Agency, Karolinska Institutet, and Uppsala University. During the work-up and writing of the data and processing of the manuscript, Professor Yesehak Worku, Addis Ababa University, became seriously ill and has not been able to pursue and overlook the publication process as intended. The authors thank Professor Per-Olof Berggren, Karolinska Institutet, for supplying ob/ob mice for the investigations.

\section{Author contributions}

All authors contributed toward data analysis, drafting and critically revising the paper, gave final approval of the version to be published, and agree to be accountable for all aspects of the work.

\section{Disclosure}

The authors report no conflicts of interest in this work.

\section{References}

1. Bailey CJ, Day C. Traditional plant medicines as treatments for diabetes. Diabetes Care. 1989;12:553-564.

2. Khan I, AbdElsalam NM, Fouad H, Tariq A, Ullah R, Adnan M. Application of ethnobotanical indices on the use of traditional medicines against common diseases. Evid Based Complement Alternat Med. 2014; 2014:635371.

3. Oubré AY, Carlson TJ, King SR, Reaven GM. From plant to patient: an ethnomedical approach to the identification of new drugs for the treatment of NIDDM. Diabetologia. 1997;40:614-617.

4. Alarcon-Aguilar FJ, Roman-Ramos R, Flores-Saenz JL, Aguirre-Garcia F. Investigation on the hypoglycaemic effects of extracts of four Mexican medicinal plants in normal and alloxan-diabetic mice. Phytother Res. 2002; $16: 383-386$.

5. Haddad PS, Depot M, Settaf A, Cherrah Y. Use of antidiabetic plants in Morocco and Quebec. Diabetes Care. 2001;24:608-609.

6. Jung M, Park M, Lee HC, Kang YH, Kang ES, Kim SK. Antidiabetic agents from medicinal plants. Curr Med Chem. 2006;13:1203-1218.

7. Ahmed MF, Ibrahim M, Thayyil H, Zameeruddin K. Antioxidative activity of Melia azedarach Linn leaf extract. Iran J Pharmacol Therap. 2008;7:31-34.

8. Ayyanar M, Ignacimuthu S. Ethnobotanical survey of medicinal plants commonly used by Kani tribals in Tirunelveli hills of Western Ghats, India. J Ethnopharmacol. 2011;134:851-864.

9. Carpinella MC, Miranda M, Almiron WR, Ferrayoli CG, Almeida FL, Palacios SM. In vitro pediculicidal and ovicidal activity of an extract and oil from fruits of Melia azedarach L. J Am Acad Dermatol. 2007; $56: 250-256$.

10. Wandscheer CB, Duque JE, da Silva MA, Fukuyama Y, Wohlke JL, Adelmann J, Fontana JD. Larvicidal action of ethanolic extracts from fruit endocarps of Melia azedarach and Azadirachta indica against the dengue mosquito Aedes aegypti. Toxicon. 2007;44:829-835.
11. Descalzo AM, Coto C. Inhibición del virus de pseudorrabia (Suid herpesvirus 1) por acción de un antiviral aislado de hojas de Melia azedarach [Inhibition of the pseudorabies virus (Suis herpesvirus 1) by an antiviral agent isolated from the leaves of Melia azedarach]. Rev Argent Microbiol. 1989;21:133-140. Spanish.

12. Choudhary DN, Singh JN, Verma SK, Singh BP. Antifertility effects of leaf extracts of some plants in male rats. Indian J Exp Biol. 1990;28:714-716.

13. Khan MF, Rawat AK, Pawar B, Gautam S, Srivastava AK, Negi DS. Bioactivity-guided chemical analysis of Melia azedarach L. (Meliaceae), displaying antidiabetic activity. Fitoterapia. 2014;98:98-103.

14. Herbert V, Lau KS, Gottlieb CW, Bleicher SJ. Coated charcoal immunoassay of insulin. J Clin Endocrinol Metab. 1965;25:1375-1384.

15. Levin F, Edholm T, Ehrström M, et al. Effect of peripherally administered ghrelin on gastric emptying and acid secretion in the rat. Regul Pept. 2005; 131:59-65.

16. Beddow SA, Samuel VT. Fasting hyperglycemia in the Goto-Kakizaki rat is dependent on corticosterone: a confounding variable in rodent models of type 2 diabetes. Dis Mod Mech. 2012;5:681-685.

17. Warmington SA, Tolan R, McBennett S. Functional and histological characteristics of skeletal muscle and the effects of leptin in the genetically obese (ob/ob) mouse. Int J Obes Relat Metab Disord. 2000;24:1040-1050.

18. Akash MS, Rehman K, Chen S. Goto-Kakizaki rats: its suitability as non-obese diabetic animal model for spontaneous type 2 diabetes mellitus. Curr Diabetes Rev. 2013;9:387-396.

19. Edholm T, Cejvan K, Abdel-Halim SM, Efendic S, Schmidt PT, Hellström PM. The incretin hormones GIP and GLP-1 in diabetic rats: effects on insulin secretion and small bowel motility. Neurogastroenterol Motil. 2009;21:313-321.

20. Näslund E, Gutniak M, Skogar S, Rössner S, Hellström PM. Glucagonlike peptide 1 increases the period of postprandial satiety and slows gastric emptying in obese men. Am J Clin Nutr. 1998;68:525-530.

21. Jialal I, Devaraj S, Adams-Huet B, Chen X, Kaur H. Increased cellular and circulating biomarkers of oxidative stress in nascent metabolic syndrome. J Clin Endocrinol Metab. 2012;97:E1844-E1850.

22. Anderson J, Coulson R, Grassick BD, Morris BA, Thomas WD, Tomlihson RW, Woodroffe F. Clinical and metabolic study in diabetic patients treated with glibenclamide. Br Med J. 1970;2:568-570.

23. Kruszynska YT, Olefsky JM. Cellular and molecular mechanisms of noninsulin dependent diabetes mellitus. J Investig Med. 1996;44:413-428.

24. Attele AS, Zhou YP, Xie JT, et al. Antidiabetic effects of Panax ginseng berry extract and the identification of an effective component. Diabetes. 2002;51:1851-1858.

25. Ginsberg H, Kimmerling G, Olefsky JM, Reaven GM. Demonstration of insulin resistance in untreated adult onset diabetic subjects with fasting hyperglycemia. J Clin Invest. 1975;55:454-461.

26. Reaven GM. Insulin resistance in noninsulin-dependent diabetes mellitus. Does it exist and can it be measured? Am J Med. 1983;74:3-17.

27. Näslund E, King N, Mansten S, et al. Prandial subcutaneous injections of glucagon-like peptide-1 cause weight loss in obese human subjects. Br J Nutr. 2004;91:439-446.

28. Chattopadhyay RR. Possible mechanism of antihyperglycemic effect of Azadirachta indica leaf extract. Part IV. Gen Pharmacol. 1996;27:431-434.

29. Khosla P, Bhanwra S, Singh J, Seth S, Srivastava RK. A study of hypoglycaemic effects of Azadirachta indica (Neem) in normal and alloxan diabetic rabbits. Indian J Physiol Pharmacol. 2000;44:69-74.

30. Chattopadhyay RR, Chattopadhyay RN, Nandy AK, Poddar G, Maitra SK. The effect of fresh leaves of Azadirachta indica on glucose uptake and glycogen content in the isolated rat hemi diaphragm. Bull Calcutta Sch Trop Med. 1987;35:8-12. 
The Journal of Experimental Pharmacology is an international, peerreviewed, open access journal publishing original research, reports, reviews and commentaries on all areas of laboratory and experimental pharmacology. The manuscript management system is completely online and includes a very quick and fair peer-review system.

Submit your manuscript here: https://www.dovepress.com/journal-of-experimental-pharmacology-journal

Visit http://www.dovepress.com/testimonials.php to read real quotes from published authors. 